\title{
AUTO SUMMARIZATION BASED EIGRP (AS-EIGRP) AND IT'S COMPARISON WITH EIGRP
}

\author{
Ravjot Singh Syal ${ }^{1}$, Kamaljit Kaur ${ }^{2}$ \\ ${ }^{I}$ M.Tech Student, CSE Department, Sri Guru Granth Sahib World University, Fatehgarh Sahib, Punjab, India \\ ${ }^{2}$ Assistant Professor, CSE Department, Sri Guru Granth Sahib World University, Fatehgarh Sahib, Punjab, India
}

\begin{abstract}
Wireless Network spreads everywhere now from one place to another. Using a wireless network also requires optimization of network in a better way it in such a way that its throughput is improved to an extent that the packet always follows the shortest path and routers always have the information of each and every node in the network. This paper discusses comparison study of AS- EIGRP (EIGRP is combined with Route Summarization) and EIGRP (Enhanced Interior Gateway Protocol). Results show how the AS-EIGRP performed better than EIGRP in different network metrics.
\end{abstract}

Keywords: EIGRP, AS-EIGRP, Route-Summarization, Wireless Network.

\section{INTRODUCTION}

Wireless Network consists of small nodes with sensing, computation, and wireless communications capabilities over short distances. Each sensor collects data from the monitored area and then it acknowledges data back to the source for the successful delivery of it. AS- EIGRP is compared with EIGRP on the basis of network metrics such as delay, retransmission etc.

\section{EXISTING WORK}

Wireless Routing aims at reliable transmission of packets from source to destination, communication between routers along with providing various features like security, better time management and optimal path selection.

Raj Kumar Singh, A.K.Jain [1]: Inthis paper discussion of the two operating modes of the IEEE 802.11 is provided along with the an overview of a comprehensive list of research issues and challenges of the wireless network like signal fading problem, mobility problem, power and energy, data rate enhancement, security and the quality of service issues problems of the wireless network.

Ravjot Singh Syal, Navpreet Kaur Walia [2]: In this paper the role of routing protocols for active transmission of data is shown. Various routing protocols were implemented (Viz. OSPF, EIGRP, RIP) in the network and their performance was measured out of which the performance of EIGRP was higher than other routing protocols.

Kuwar Pratap Singh, P.K.Gupta, G.Singh [3]: In this paper, authors have considered the Enhanced Interior Gateway Routing Protocol (EIGRP) for IPv6 as a routing protocol, that uses classless routing schemes based on diffusion update algorithm (DUAL) for calculating a shortest path from source to destination IPv6 is used along with EIGRP protocol which removes the limitations imposed by IPv4 and provides the large number of address space.

Prachi Thakur, Yogesh Bansal [4]: In this paper, different types of routing protocols available such as static and dynamic routing protocols are surveyed. Three routing protocols, RIP (Distance vector protocol), OSPF (Link state Protocol) and EIGRP (Hybrid Protocol) are analyzed and a depth comparison of the respective protocols is done on the basis of complexity, bandwidth etc.

Archana C [5]: In this paper, comparative study of RIP, OSPF \& EIGRP is done, it is shown how using a routing protocol routers communicate with each other, disseminating information that enables them to select routes between any two nodes on a computer network.

Komal Gehlot, N.C. Barwar [6]: This paper is a study based on simulation for comparative performance evaluation between EIGRP and OSPF routing protocols for real time applications by using Best-Effort and Quality of service method in OPNET simulator. The evaluation is done based on different aspects such as traffic sent and received, packet delay variation, packet end-to-end delay as well as voice and video traffic sent/received using simulator.

Y.Navaneeth Krishnan, Shobha G [7]: In this paper study of two eminent protocols, Enhanced Interior Gateway Routing Protocol (EIGRP) and Open Shortest Path First (OSPF) protocols is evaluated. Evaluation of these routing protocols is performed based on the quantitative metrics such as Convergence Time, Jitter, End-toEnd delay. The evaluation results show that EIGRP routing protocol provides a better performance than OSPF routing protocol for real time applications

Haresh N. Patel, Rashmi Pandey [8]: This paper focuses on route redistribution and route summarization of different intra-domain routing protocols such as EIGRP and OSPF. 
multiple routing protocols and Autonomous systems are made to communicate in the Hybrid networks (OSPF vs. EIGRP protocols with Different AS) then route redistribution is necessary to advertise route from source network to destination.

Vishal Sharma, Rajneesh Narula, Sumeer Khullar [9]: This paper compares the performance of intra-domain routing protocols such as Enhanced Interior Gateway Protocol (EIGRP) and Interior Gateway Protocol (IGRP) of IEEE 802.3 LAN by evaluating various parameters including Network convergence time, Delay Variation, Throughput, Utilization, Queuing Delay and IP Processing Delay.

Ankit Sharma, Sheilly Padda [10]: In this paper a network model of Cisco routers has been employed in a network simulation software 'packet tracer'. Eventually an EIGRP routing protocol has been configured and run on a network model. The successful communication is established between different hosts present in the network

Ttiphon Krinpayorm, Suwat Pattaramalai [11]: This research is a performance comparison of router protocol between OSPF and EIGRP when an internet link fails. Since OSPF and EIGRP protocols are mostly used nowadays, the retransmission time and rerouting time is calculated from both protocols when there is a failure link in a data transmission path.

Pritesh Kumar Jain, Manoj Sindhwani, Shippu Sachdeva [12]:This Paper a comparison of routing methodology based on logical addressing using subnetting is done, which is a concept of Dynamic Host Configuration Protocol (DHCP).

Archana Kudtarkar, Reena Sonkusare, Dayanand Ambawade [13]: In this paper, Comparison is studied among Interior Gateway Protocols (IGP) protocols with weighted-faired queuing (WFQ) technique on different scenarios using OPNET (Optimized Network Engineering Tool).

\section{COMBINING EIGRP AND AUTO}

\section{SUMMARIZATION}

1. Deploying a Wireless Network.

2. Configuring various zones in the network.

3. Checking for loops in the network avoid if present.

4. Update information of neighbor routers in the routing table.

5. Update information of the various paths in the network.

6. If a network node dies then selecting the next shortest path.

7. Performing Route Summarization.

\section{EXPERIMENTAL SETUP}

CISCO Packet Tracer is used as simulation tool. Cisco packet tracer is Cisco's easy option and is mainly used for CCNA training purposes Packet tracer works perfectly within its own environment allowing access to all its devices IOS's so there is no need to have to get any more software or plugins to use all its functions

Table 4.1: Parameters Used

\begin{tabular}{|l|l|}
\hline Simulation Parameter & Value \\
\hline Simulator & Cisco Packet Tracer \\
\hline Frequency Bandwidth & $20 \mathrm{Mhz}$ \\
\hline Packet Size & 1500 bytes \\
\hline Channel Frequency & $1-2.412 \mathrm{GHz}$ \\
\hline Bandwidth & $100 \mathrm{Mbps}$ \\
\hline Routing protocol & EIGRP \\
\hline Duplex Mode & $\begin{array}{l}\text { Half for Access Point/ } \\
\text { full For Switches/ } \\
\text { Routers }\end{array}$ \\
\hline Encryption type & $\begin{array}{l}\text { WEP (Wired Equivalent } \\
\text { Privacy) }\end{array}$ \\
\hline $\begin{array}{l}\text { Retransmission Timeout in } \\
\text { milliseconds }\end{array}$ & 1000 ms \\
\hline Number of Routers & 5 \\
\hline Number of Switches & 5 \\
\hline Number of Access Points & 4 \\
\hline
\end{tabular}

\section{COMPARATIVE ANALYSIS}

\subsection{Comparative Analysis of EIGRP and AS- EIGRP on the basis of Data Dropped}

Data Dropped: The amount of data is dropped in the network due to any failure or loss in the network and it does not gets delivered to the destination. It is expressed in bits or packets

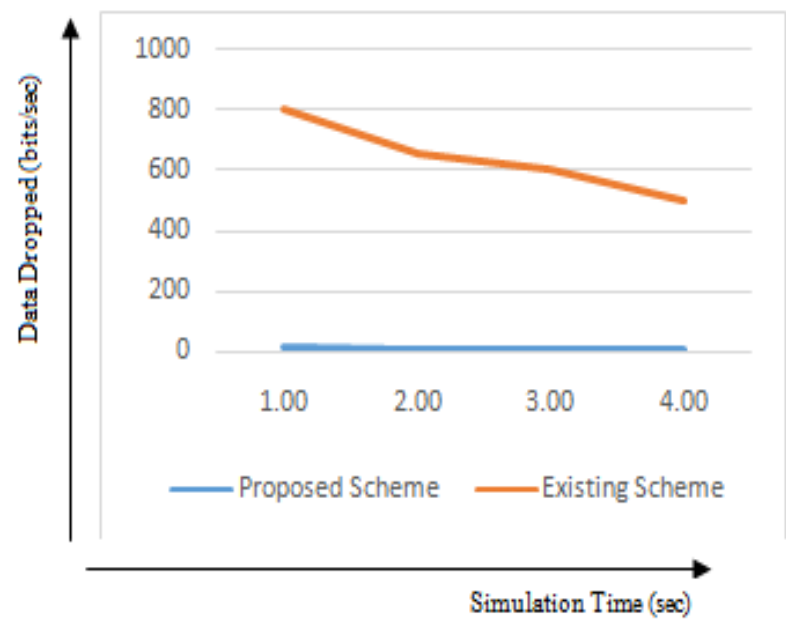

Fig 5.1Comparison of EIGRP and AS-EIGRP on the basis of Data Dropped

The graph shows the data dropped of the two techniques present and previous. Here $\mathrm{x}$-axis represents simulation time in seconds and $y$-axis represents data dropped in case of existing scheme is approx. $800 \mathrm{bits} / \mathrm{sec}$ while in case of proposed scheme it is $11 \mathrm{bits} / \mathrm{sec}$ and data drop in ASEIGRP is very less than EIGRP. 


\subsection{Comparative Analysis of EIGRP and AS-} EIGRP on the basis of Load

Load: The amount of data is that is carried by a network. It is expressed as bits/sec or packets/sec.

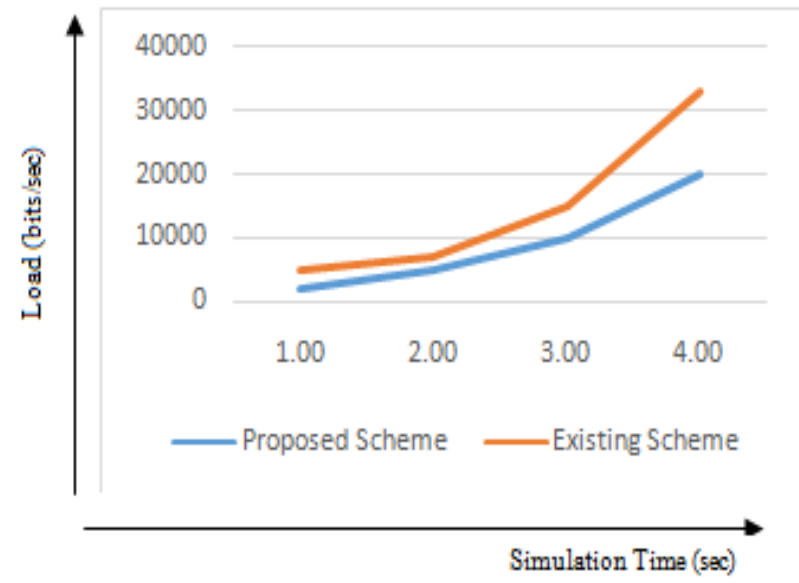

Fig 5.2Comparison of EIGRP and AS-EIGRP on the basis of Load

The graph shows the comparison of existing technique that is EIGRP and proposed that is AS-EIGRP. Here $\mathrm{x}$-axis represents simulation time in seconds and $y$-axis represents load and representation of load in EIGRP and AS-EIGRP. In case of existing scheme is approx. $35000 \mathrm{bits} / \mathrm{sec}$ while in case of proposed scheme it is $20000 \mathrm{bits} / \mathrm{sec}$ and load in EIGRP is more than AS-EIGRP.

\subsection{Comparative Analysis of EIGRP and AS-}

\section{EIGRP on the basis of Delay}

Delay: The amount of data is that is carried by a network. It is expressed as bits/sec or packets/sec. The delay of a network specifies how long it takes for a bit of data to travel across the network from one node or endpoint to another.

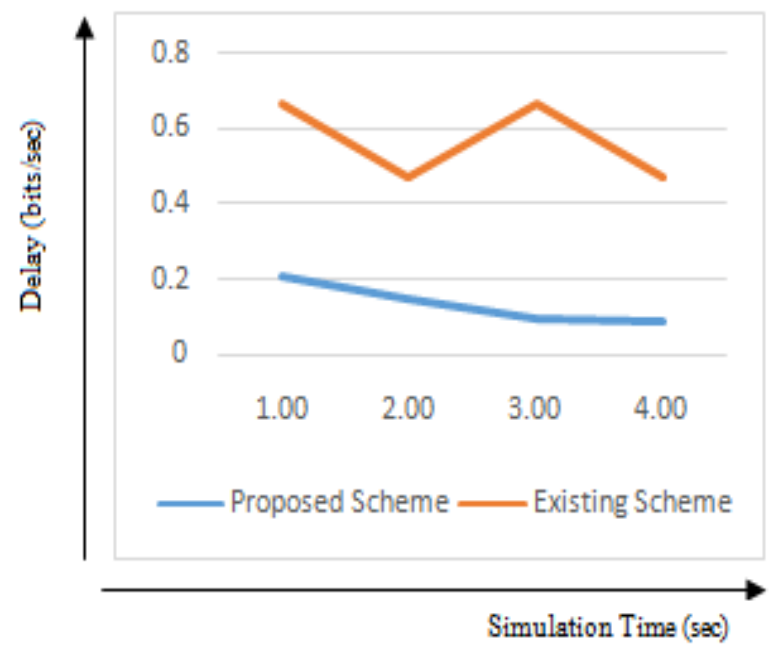

Fig 5.3Comparison of EIGRP and AS-EIGRP on the basis of Delay
The graph shows the comparison of existing technique that is EIGRP and proposed that is AS-EIGRP. Here $\mathrm{x}$-axis represents simulation time in seconds and $y$-axis represents delay. In case of existing scheme delay is $0.5 \mathrm{sec}$ while in case of proposed scheme it is $0.01 \mathrm{sec}$ i.e. delay in EIGRP is more than AS-EIGRP.

\subsection{Comparative Analysis of EIGRP and AS- EIGRP on the basis of Retransmission}

Delay: It is the number of attempts that is taken by source to deliver a message to the destination. It is represented in bits/sec. Simulation time is the total time taken for each simulation to run and simulate the entire environment of the network.

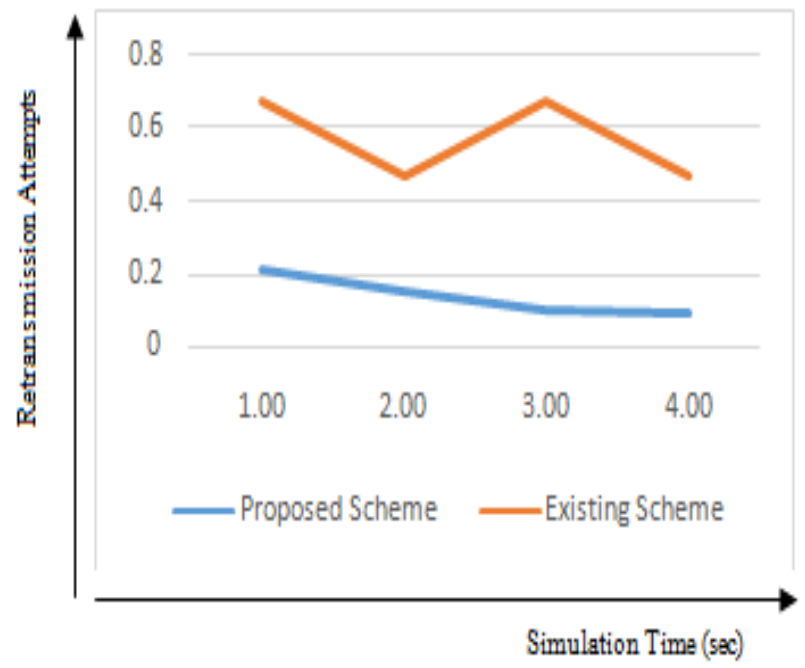

Fig 5.4Comparison of EIGRP and AS-EIGRP on the basis of Retransmission

The graph shows the comparison of existing technique that is EIGRP and proposed that is AS-EIGRP. Here $\mathrm{x}$-axis represents simulation time in seconds and $y$-axis represents Retransmission Attempts. In case of existing scheme it is $0.57 \mathrm{bits} / \mathrm{sec}$ while in case of proposed scheme it is 0.26 bits/sec i.e. Retransmission Attempts in EIGRP is more than AS-EIGRP.

\section{CONCLUSION}

In this paper AS-EIGRP is compared with EIGRP. In ASEIGRP combination of Auto Summarization with EIGRP is made. The network is made more efficient and more secure than EIGRP. AS-EIGRP showed better time management in the network. Using AS-EIGRP the data dropped and other quality parameters are also improved like delay, load and throughput. 


\section{REFERENCES}

[1] Raj Kumar Singh, Dr.A.K.Jain "Research Issues in Wireless Networks" International Journal of Advanced Research in Computer Science and Software Engineering Volume 2, Issue 4, April 2012, ISSN: 2277 128X.

[2] Ravjot Singh Syal, Navpreet Kaur Walia“Survey on EIGRP Protocol in Wireless Networks", 4th International Conference on Advancements in Engineering \& Technology (ICAET-2016), March 18 19,2016

[3] Kuwar Pratap Singh, P.K.Gupta, G.Singh "Performance Evaluation of Enhanced Interior Gateway Routing Protocol in IPv6 Network" International Journal of Computer Applications (0975 8887) Volume 70- No.5, May 2013.

[4] Prachi Thakur, Yogesh Bansal "Survey of Ip Routing Protocols" International Journal of Advanced Research in Computer Science and Software Engineering" Volume 4, Issue 7, July 2014, ISSN: 2277 128X.

[5] Archana C "Analysis of RIPv2, OSPF, EIGRP Configuration on router Using CISCO Packet tracer" International Journal of Engineering Science and Innovative Technology (IJESIT) Volume 4, Issue 2, March 2015, ISSN: 2319-5967.

[6] Komal Gehlot, N.C. Barwar "Performance Evaluation of EIGRP and OSPF Routing Protocols in Real Time Applications" International Journal of Emerging Trends \& Technology in Computer Science (IJETTCS) Volume 3, Issue 1, January - February 2014, ISSN 2278-6856.

[7] Y.Navaneeth Krishnan, Dr Shobha G "Performance Analysis of OSPF and EIGRP Routing Protocols for Greener Internetworking" Proceedings of 2013 International Conference on Green High Performance Computing March 14-15, 2013, India.

[8] Haresh N. Patel, Prof. Rashmi Pandey "Extensive Reviews of OSPF and EIGRP Routing Protocols based on Route Summarization and Route Redistribution." Haresh N. Patel Int. Journal of Engineering Research and Applications, ISSN: 2248-9622, Vol. 4, Issue 9( Version 4), September 2014, pp.141-144.

[9] Vishal Sharma, Rajneesh Narula, Sumeer Khullar "Performance Analysis of IEEE 802.3 using IGRP and EIGRP Routing Protocols" International Journal of Computer Applications (0975 - 8887) Volume 44No13, April 2012.

[10] Er.Ankit Sharma, Er.Sheilly Padda "Configuring an EIGRP based Routing Model" International Journal of Scientific and Research Publications, Volume 2, Issue 2, February 2012, ISSN 2250-3153.

[11] Ttiphon Krinpayorm, Suwat Pattaramalai "Link Recovery Comparison Between OSPF \& EIGRP” 2012 International Conference on Information and Computer Networks (ICICN 2012) IPCSIT vol. 27 (2012) (C) (2012) IACSIT Press, Singapore.

[12] Pritesh Kumar Jain, Manoj Sindhwani, Shippu Sachdeva "Comparative Study of Routing Protocols with Subnetting Implementation in Cisco Packet Tracer",International Journal of Advanced Research in
Computer Science and Software Engineering, Volume 4, Issue 12, December 2014,ISSN: 2277 128X.

[13] Archana Kudtarkar, Reena Sonkusare, Dayanand Ambawade "Performance Analysis of Routing Protocols for Real Time Application", International Journal of Advanced Research in Computer and Communication Engineering Vol 3, Issue 1, January 2014. 